\title{
Prevalence of COVID-19: A Look behind the Scenes from the UAE and India
}

\author{
Samir Haj Bloukh ${ }^{1}$, Annis A. Shaikh ${ }^{2}$, Habib M. Pathan ${ }^{2}$ and Zehra Edis 3,* \\ 1 College of Pharmacy and Health Science, Ajman University, PO Box 346, Ajman, United Arab Emirates; \\ s.bloukh@ajman.ac.ae \\ 2 Advanced Physics Laboratory, Department of Physics, Savitribai Phule Pune University, Pune - 411 007; \\ pathan@physics.unipune.ac.in; annisshaikh786@gmail.com \\ 3 College of Pharmacy and Health Science, Department of Pharmaceutical Sciences, Ajman University, PO \\ Box 346, Ajman, United Arab Emirates; z.edis@ajman.ac.ae \\ * Correspondence: z.edis@ajman.ac.ae; Tel.: +971-56-694-7751 (Z.E.)
}

\begin{abstract}
Mankind faces a coronavirus pandemic originating from a seafood market in Wuhan, China since December 2019. The pathogen was named novel coronavirus (n-CoV) and bats are the identified key reservoir. The coronavirus disease 2019 (COVID-19) quickly spread over China across the globe, turned into a pandemic with exponentially increasing numbers of cases and significant mortality rate. China reacted with lockdowns and strict control measurements to prevent spreading the virus. The treatment of severe cases was hampered by lack of specific vaccines. Vaccine-development and production is a painstaking process and can only be enforced by international cooperation. Different supportive treatment options surfaced due to combinations of antiviral agents with antibiotic drugs. Elderly, male, immune-suppressed patients with co-morbidities showed a high mortality rate. Health literacy, strong immune system, adequate serum 25-hydroxyvitamin D (25(OH)D) concentrations and healthy life style choices can support fast recovery. Antibiotic resistance needs to be addressed by development of new generation antimicrobials against nosocomial infections in preparation for future outbreaks. Plant-biosynthesis of nanomaterials and antiseptics may help in prevention and recovery rate. Prevalence of COVID-19 maybe inversely related to BCG vaccination, endemicity of malaria, humidy and temperature but directly with latitude. Recommendations to prevent the spread of COVID-19 should be followed strictly.
\end{abstract}

Keywords: COVID-19; SARS-CoV-2; human coronavirus; control; vitamin D; antibiotic resistance; antimicrobial agents; BCG; malaria; climate; latitude

\section{Introduction}

In late December 2019, a novel coronavirus (CoV) was identified as a pathogen that caused the outbreak of an illness in the Chinese city of Wuhan and was officially named as 2019-nCoV by the World Health Organization (WHO). Due to implications in the respiratory system, it was called severe acute respiratory syndrome coronavirus 2 (SARS-CoV-2) and later on coronavirus disease 2019 (COVID-19). On 30 January 2020, WHO declared COVID-19 as a six public-health emergency of international concern [1]. This paper closely consolidates the morphology, clinical manifestations, diagnosis, treatments, preventive measures and future trends for research of this novel coronavirus $(\mathrm{n}-\mathrm{CoV})$.

\section{Human Coronavirus- a Brief History}

Human coronaviruses ( $\mathrm{HCoVs}$ ), a large family of Coronaviruses are non-segmented, enveloped, positive-sense, single-strand ribonucleic acid (RNA) viruses [2]. HCoVs can infect animals and also 
humans, causing respiratory, hepatic, and neurologic diseases [3]. CoV are divided into four genera: alpha-coronavirus $(\alpha)$, beta-coronavirus $(\beta)$, gamma-coronavirus $(\gamma)$ and delta-coronavirus $(\delta)$ [2-5]. Human coronaviruses were identified in late 1960 and known to infect human as well as mammals and birds. Until now, six HCoVs were identified (Table 1).

Table 1. Human coronaviruses since 1960.

\begin{tabular}{cccccr}
\hline No. & Generation & Name & $\begin{array}{c}\text { Year of } \\
\text { Identification }\end{array}$ & $\begin{array}{c}\text { Place of } \\
\text { Identification }\end{array}$ & Ref. \\
\hline 1 & Alpha $(\alpha)$ & HCoVs-229E & 1960 & - & {$[2-5]$} \\
\hline 2 & Beta $(\beta)$ & HCoVs-OC43 & 1960 & - & {$[2-5]$} \\
\hline 3 & Beta $(\beta)$ & SARS-CoV & 2002 & Guangdong, & {$[6,7]$} \\
& Alpha $(\alpha)$ & HCoVs-NL63 & 2004 & Netherlands & {$[6,7]$} \\
\hline 4 & Beta $(\beta)$ & MERS-CoV & 2012 & Saudi Arabia & {$[8]$} \\
\hline $\mathbf{6}$ & Beta $(\beta)$ & SARS-CoV-2/n-CoV-19 & $\mathbf{2 0 1 9}$ & Wuhan, China & {$[8]$} \\
\hline
\end{tabular}

In 2003, a virus was identified in Guangdong province in China causing severe acute respiratory syndrome (SARS). Later on the virus was confirmed as a member of Beta-coronavirus family and was named as SARS-CoV [6,7]. A decade later in 2012, a couple of Saudi Arabian nationals were identified to be infected with another coronavirus which belongs to Beta $(\beta)$ coronavirus family named as the Middle East respiratory syndrome coronavirus (MERS-CoV). In 2019, the novel CoV caused the outbreak of a SARS-like illness in the Chinese city of Wuhan and was termed as severe acute respiratory syndrome coronavirus-2 (SARS-CoV-2) [8].

\section{Origin and Transmission}

Source of origination and transmission are relevant factors for the development of preventive strategies and treatment protocols. SARS coronavirus may have circulated in humans before causing the outbreak in 2003 [9]. Rhinolophus bats were identified of having anti-SARS-CoV antibodies suggesting the bats as a source of virus [10]. The Middle East respiratory syndrome (MERS) coronavirus (2012) in Saudi Arabia belongs to beta-coronavirus originating from camels as primary host [11]. In case of COVID-19 only bats were identified as key reservoirs [12, 13]. COVID-19 originated in Wuhan and was carried through migration by the population to different cities and other provinces around Hubai [13]. Infection rates increased rapidly and were controlled by a lockdown on cities in the Hubai province followed by further control mechanisms for the whole country $[13,14]$. This approach prevented effectively the exponential increase of infection on national basis $[13,14]$.

\section{Morphology}

The word 'corona' stands for crown in Latin, which represents crown-like spikes on the outer surface of the virus. Coronaviruses are enveloped type viruses with a positive sense single-stranded RNA genome [2]. They have the largest genome among all RNA viruses, typically ranging from 27 to $32 \mathrm{~kb}$ size and are $65-125 \mathrm{~nm}$ in diameter [2,15]. The genome is packed inside a helical capsid formed by the nucleocapsid protein (N) and further surrounded by an envelope [16]. At least three structural proteins are associated with the viral envelope [16]. The envelope protein (E) and the membrane protein $(\mathrm{M})$ are involved in virus assembly, whereas the spike protein (S) mediates virus entry into host cells. Among these structural proteins, the spike-like structure from the virus surface renders the crown-like appearance (Figure 1) [16]. 


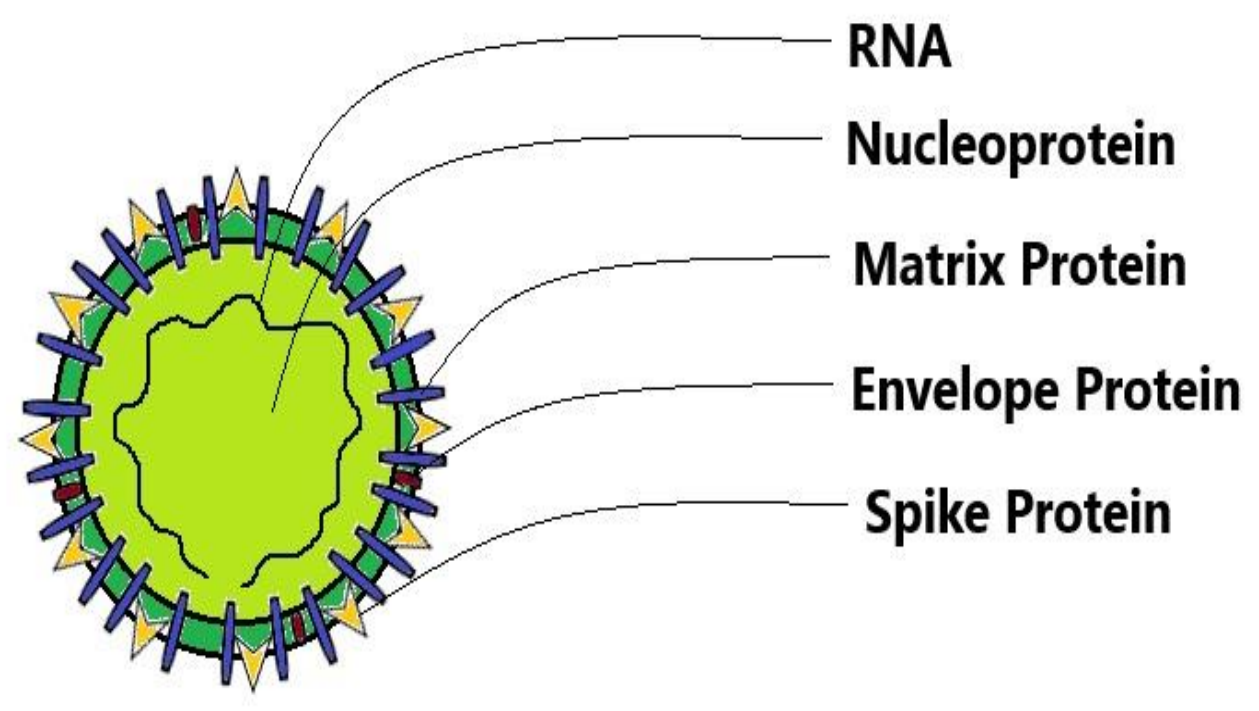

Figure 1. Morphology of the human coronavirus COVID-19.

\section{Clinical Manifestations}

\subsection{Patient Profile and Environmental Factors}

The patient characteristics in the ongoing COVID-19 pandemic reveal several hints about the susceptibility and the severity of the disease. A recent review reporting clinical and demographic characteristics of 44,672 COVID-19 cases in China showed that everyone without age limitation is susceptible [17]. Every person in the same vicinity of a positive case with or without symptoms can be infected. This can happen by respiratory droplets carrying the virus or through contact with infected surfaces and subsequently touching mouth, nose and eyes [18]. The virus is transmitted from an infected carrier to anyone in close contact without any limitation [17]. Older patients and immunocompromised individuals succumb most likely to a severe course of the disease due to pneumonia [17]. Progression of $\mathrm{CoV}$ pneumonia is directly related to advanced age, history of metabolic syndrome, smoking and other chronic conditions like cardiovascular disease [19]. According to a recent review, 25-hydroxyvitamin D $(25(\mathrm{OH}) \mathrm{D})$ concentrations may play a relevant role in the progression of the disease [20]. Sufficient serum $(25(\mathrm{OH}) \mathrm{D})$ concentrations ensure cellular immunity, reduce the risk of infections caused by microorganisms, protect against metabolic syndrome and other chronic illnesses [20]. Vitamin D levels are associated with environmental, biological and socio-economical factors [21]. Increased time spent indoors by screen-based entertainment, sedentary lifestyle, less outdoor physical activity are directly related to poor endogenous vitamin D synthesis $[21,22,23]$. Vitamin D deficiency is prevalent in the northern hemisphere due to decreased solar irradiation especially in the winter months [20,21]. COVID-19 infection rates are showing exponential growth in northern hemisphere countries, which started in the month of December 2019 [24,25]. Higher susceptibility of advanced age individuals to COVID-19 may confirm this hypothesis. Commonly, serum 25-hydroxyvitamin D (25(OH)D) concentrations are lower in elderly individuals and geriatric patients due to indoor dwelling, physical inactivity and increased pharmaceutical drugs intake $[20,21,26]$. Sufficient serum vitamin D levels may have an impact on recovery rate and survival of patients during illness [20-23]. High levels of fatality were recorded in advanced age patients with compromised immune system by diabetes, hypertension, 
cardiovascular disease during SARS-CoV, MERS-CoV and COVID-19 [27-29]. Deng et al. compared in their study the characteristics of the fatality group of patients with the recovered group [29]. Advanced age, dyspnea, comorbidities, low oxygen-saturation, high white blood cell (WBC) count, low lymphocytes and high levels C-reactive protein (CRP) are significant indicators to mortality [29]. Patients in this group had also complications like acute respiratory distress syndrome, acute cardiac injury, shock, acute kidney injury and disseminated intravascular coagulation [29]. A study from Iran identified higher age and impaired immune system due to diabetes as risk factors leading to severe pneumonia [30]. Hookah smoking had a relevant role in spreading COVID-19 and increased the susceptibility of younger people to COVID-19 [30]. These findings can be explained by immune-suppressing effects of hookah smoking and the related socialization pattern during COVID-19 outbreak. Preventive measures, like social-distancing were not followed strictly by the population and not enforced harshly by the government. Delayed implementation of preventive measurements will be only successful if social distancing is practiced within the household. Asymptomatic- or mild cases can transmit the disease fastly within their household while very family is asked to stay at home. Especially vulnerable, high risk individuals are under risk to be infected and to progress towards severe COVID-19 disease. Luo et al. concluded in their prospective cohort study on contact modes and the risk of transmitting COVID-19 that highest in household contacts [31]. Stay at home campaigns needs awareness of every individual to avoid close contact, which can be dangerous for the whole community within the same household.

\subsection{Incubation Period}

The incubation period means the time between being affected by the virus and beginning to have symptoms of the disease. In case of COVID-19, the incubation period ranges from 1-14 days [29]. A recent review revealed the mean or median incubation time of COVID-19 is less than 13 days and should be even considered to be lower than to 4-6 days, which is similar to SARS-CoV with 4.4 and MERS-CoV 5.5 days [17].

\subsection{Symptoms}

Symptoms of COVID-19 include a wide range of conditions depending on pre-existing comorbidities and age [28]. Wu et al. reported mild symptoms for $81 \%$, development of severe health conditions $14 \%$ and critically ill for $5 \%$ of cases in China during the course of COVID-19 disease [28]. Inversely to those findings, Chen et al. revealed that pediatric patients had good recovery rates and developed only mild symptoms like fever and cough [32]. $80 \%$ of the patients in a study developed first mild fever [33]. Half of these cases developed high fever, while atypically $20 \%$ had no fever at all [33]. Additional symptoms were coughing, myalgia and fatigue [33]. Few patients experienced problems in the cardiovascular, nervous and digestive systems overshadowing the diagnosis of COVID-19 [33].

A review including 61 studies from eleven counties reports highest percentage of symptoms for fever, followed by cough (with and without sputum), muscle aches, fatigue, dyspnea, headache, sore throat and gastrointestinal problems [34]. In general the clinical symptoms of COVID-19 are similar to other viral respiratory diseases, which impedes swift diagnosis [34]. The delay in diagnosis, combined with factors such as being male with advanced age over 60 and severe pneumonia resulted in high death rates with a total mortality of 3\% [34]. Epidemiological studies confirm higher mortality in elderly, male patients, while clinical symptoms and diagnosis in COVID-19 remain non-specific [34]. Successful control of COVID-19 is only possible through implementing effective mechanisms of diagnosis, isolation and treatment. Any suspected case needs to go thorough diagnosis process, which includes virological assay and early imaging [34].

Symptoms of COVID-19 are non-specific and it can range from no symptoms (asymptomatic) to severe pneumonia and death (Table 2) [33-37]. 
Table 2. Symptoms and complications of COVID-19.

\begin{tabular}{cccc}
\hline No. & Symptoms & Complications & Ref. \\
\hline 1 & Dry cough & Pneumonia & {$[33-36]$} \\
\hline 2 & Fever & Kidney Failure & {$[35,36]$} \\
\hline 3 & Sore Throat & Sepsis & {$[33-36]$} \\
\hline 4 & Headache & Acute Respiratory Distress Syndrome & {$[33-36]$} \\
& & (ARDS) & \\
\hline 5 & Fatigue & Acute Heart Injury & {$[33-36]$} \\
\hline 6 & Body ache and Pain & Weakness & {$[33-36]$} \\
\hline 7 & Diarrhea & Dehydration & {$[33-36]$} \\
\hline 8 & Runny or Stuffy Nose & ARDS & {$[35,36]$} \\
\hline 9 & Shortness of Breath & ARDS & {$[35,36]$} \\
\hline 10 & Depression & & {$[37]$} \\
\hline
\end{tabular}

The COVID-19 global outbreak caused panic, insecurity and depression due to the fast rate of infection, asymptomatic cases with high transmission potential, non-specific symptoms and the implemented control mechanisms on the public. Social distancing, isolation, insecurity of food and survival, diminishing of personal interactions, public closure, aggravated and increasing clusters of virus outbreaks leading to the collapse of the health care system, loss of jobs with sudden unemployment, financial crisis resulted in confusion, which may have an impact on health and quality of life. Panic, mental health problems and depression emerged like previously reported in MERS-CoV [37]. Health literacy in the population is a tool to measure the reaction of the public and the related health outcomes in the management of the crisis [37]. Lack of preparedness to the sudden onset of COVID-19 by governments, health care systems and organizations, as well as deficiency in diagnostic mechanisms, treatment options and management protocols further increased public insecurity globally. Human race is facing a disease without having tools to combat. According to Nguyen et al., health literacy in educated individuals is inversely related to their depression status. Increasing health literacy in the population can improve the management and control of COVID-19 and even further global pandemics [37].

\section{Diagnosis}

\subsection{Clinical Diagnosis}

In most of the infected cases with COVID-19 symptoms like fever, dry cough, fatigue, runny nose or other upper respiratory symptoms appeared as in SARS-CoV and MERS-CoV [3,33-36,38]. The diagnosis can be categorized as follows.

\subsubsection{Physical Examination}

Patients in severe condition may have shortness of breath, moist rales in lungs, weakened breath sounds, dullness in percussion [34].

\subsubsection{CT Imaging Examination}

CT imaging results vary with the patient's age, immunity status, disease stage at the time of scanning, underlying diseases, and drug interventions. In early stage of pneumonia cases, chest $x$-ray show bilateral opacities, multiple small patchy shadows, interstitial changes and thickening of pulmonary texture [34,38]. Ground-glass opacity, segmental consolidation in bilateral lungs and septal thickening can be observed more clearly in chest CT than chest x-ray [34,39]. 


\subsection{Laboratory Diagnosis}

Distinguishing COVID-19 from other known respiratory tract viruses clinically is a difficult task due to its non-specificity. Precise diagnosis can be carried out by PCR-testing and radiological study of the cases [34,40]. The two commonly known nucleic acid detection technologies for SARS-CoV-2 are reverse real-time quantitative polymerase chain reaction (rRT-qPCR) and high-throughput sequencing [41]. As far as the application of high-throughput sequencing technology in clinical diagnosis is concerned, it is limited because of its high cost and equipment dependency. So rRT-qPCR is the most common, effective and straightforward method for detecting pathogenic viruses in respiratory secretions and blood [42]. However, five patients with negative results of rRT-qPCR for SARS-CoV-2 may present with positive chest CT findings, later on confirmed that all patients were infected by SARS-CoV-2 [43]. Thus, it is essential to improve the detection rate of RT-qPCR for SARS-CoV-2 infection and RT-qPCR has some other shortcomings as well. To overcome this, a combination of repeated RT-qPCR tests and chest CT scan may be helpful. Laboratory findings in a study showed lymphopenia and abnormal C-reactive protein with a mortality rate of $0.3 \%$ [34].

\section{Treatment}

Until now, there is no vaccine or specific antiviral treatment for COVID-19 although there is an urgent demand for effective, available, and affordable drugs as a suitable response to the outbreak. WHO has announced that a vaccine for SARS-CoV-2 should be available in 18 months amids existing challenges such as funding and public interest [44]. The general treatment scheme depends on the condition of the patient. According to Liu et al. $\gamma$-immunoglobulin can be given, if symptomatic and respiratory treatment is necessary [33]. Systemic corticosteroid administration to inhibit a cytokine storm did not render any significant improvement in the prognosis of the disease [33]. In this study, antiviral treatment was given to $76.6 \%$ of the cases compared to $86.9 \%$ of cases receiving antibacterial drugs. Majority of the patients (86.9\%) needed respiratory support, nasal cannula $(62.0 \%)$, non-invasive ventilation $(24.8 \%)$, inpatient treatment $(56.2 \%)$, human $\gamma$-immunoglobolin $(32.1 \%)$ and systemic corticosteroid treatment $(29.2 \%)$. The percentage of improved and discharged patients was $32.1 \%$, while the death rate was $11.7 \%$ [33]. According to Liu et al., patients with mild symptoms like mild fever, coughing, runny nose and sore-throat should be quarantined at home without hospitalization [33]. This measurement will also prevent spreading the virus among hospitalized patients not suffering from COVID-19 [45].

In a review article on 26 publications with 1876 patients, the antiviral agents mostly used on a total of 815 patients was oseltamivir, followed by ritonavir, ganciclovir and arbidol [34]. Antibiotics were used for 836 patients linezolid, including vancomycin, meropenem, azithromycin, cefaclor, tazobactam, cefepime and moxifloxacin [34]. Other administered medications included corticosteroids, immunoglobulin, alpha-interferon, and anti-fungal agents [34]. These effectiveness of these drugs were not confimed due to lack of data [34]. Atypical pneumonia in combination with a reduced WBC, treatment failure with antibiotics is an indicator for a viral infection, including COVID-19 [46].

Remdesivir (GS-5734) and chloroquine (CQ) phosphate reportedly inhibited SARS-CoV-2 infection in vitro [47]. Hydroxychloroquine (HCQ), a less toxic derivative of chloroquine is effective in inhibiting SARS-CoV-2. Oral absorption of CQ and HCQ in humans is very efficient according to these investigations [47]. A single dose of $200-400 \mathrm{mg}$ can provide adequate lung tissue concentration to inhibit SARS-CoV-2. A single dose within every three weeks may be sufficient for prevention of SARS-CoV-2 induced lung damage [48]. Although HCQ is less toxic than CQ, its prolonged and overdose usage can still cause poisoning [49]. To make it efficient and safe, carefully designed clinical trials are required. 
Fan et al. reported recently on cepharanthine, selamectin and mefloquine hydrochloride as potential drugs against COVID-19 [50]. Cepharanthine is suggested as a promising broad-spectrum antiviral agent against pan-betacoronavirus and awaits a clinical trial [50].

\section{Preventive Measurements}

COVID-19 outbreak can be controlled by tight measurements. These include government orchestrated, meticulously organized and strictly followed control mechanisms supported and executed by the jurisdictional and executive organs. The success rate depends on political, social and economic structures of the countries, their infrastructure and level of health care system. Availability of socioeconomic power with enough resources to cope with the pressure on the health care system strengthens the effectivity of implemented control measurements. Therefore, higher income, industrialized countries may have the better opportunities to respond to the challenge [51].

Social distancing, sanitary precautions and lockdowns may help to prevent infection [52]. Many countries across the globe responded with different control mechanisms putting into account the experiences made in China, Iran and South Korea. A modeling study from Singapore investigated the impact of control measurements implemented to reduce the spread of COVID-19 [53]. The most effective method with a median average of $99.3 \%$ according to this and other studies was a combination of isolating infected cases, strict quarantine, closure of schools and workplaces $[17,53]$. The lockdown of educational establishments and offices paved the way for online based solutions, which helped to continue education and work from home.

China, Taiwan and South Korea are among those countries able to control the COVID-19 outbreak by reducing infection numbers [41,54-56]. After outbreak in Wuhan, China, the Korean government activated a 24/7 emergency response system to screen all travelers entering the country from that city [55]. They authorized an unlicensed COVID-19 testing kit and diagnosed 46,127 cases by February 26, while Japan had tested just 1,846 cases and the United States only 426 [56]. In Taiwan, proactive and comprehensive health checks on inbound passengers from Hubei province were established quickly. The production of masks, hand sanitizers and other medical items of significance were quickly controlled by the government providing a daily allotment to Taiwanese citizens [56]. Different countries implemented measurements and experienced various results in the COVID-19 pandemic (Table 3).

Table 3. Countries, their responses and outcomes in COVID-19.

\begin{tabular}{|c|c|c|c|}
\hline No. & Country & Preventive Measures/Reason & Results \\
\hline 1 & Taiwan & $\begin{array}{l}\text { Proactive and comprehensive health checks on } \\
\text { inbound passengers. } \\
\text { Establishment of an efficient and effective } \\
\text { command structure. } \\
\text { Information management by creating App. } \\
\text { Production of masks, hand sanitizer and other } \\
\text { items of medical significance were quickly } \\
\text { controlled by the government. }\end{array}$ & Under Control \\
\hline 2 & $\begin{array}{l}\text { South } \\
\text { Korea }\end{array}$ & $\begin{array}{l}\text { 24/7 Emergency response system to screen all } \\
\text { travelers. } \\
\text { Unlicensed Covid-19 Test. }\end{array}$ & Under Control \\
\hline 3 & UAE & $\begin{array}{l}\text { Educational institutes closed quickly. } \\
\text { Online teaching implemented, like in Ajman } \\
\text { University, Ajman, UAE. } \\
\text { Work from home. } \\
\text { Sanitizing huge areas in cities during nights. } \\
\text { Closure of malls except supermarkets and }\end{array}$ & Under Control \\
\hline
\end{tabular}




\begin{tabular}{|c|c|c|c|}
\hline & & $\begin{array}{l}\text { pharmacies. } \\
\text { Availability of personal protection equipment } \\
\text { and other items of medical significance ensured } \\
\text { by government. } \\
\text { Public transportation stopped. } \\
\text { Lockdown on cities. } \\
\text { Establishment of services to prevent spreading } \\
\text { COVID-19 (like Dawak Li Darek in Ajman, UAE } \\
\text { delivering chronic patients the needed drugs to } \\
\text { their doorsteps.) } \\
\text { Rising temperatures. }\end{array}$ & \\
\hline 4 & India & $\begin{array}{l}\text { Work from home. } \\
\text { All services except emergency services locked } \\
\text { down. } \\
\text { Janata curfew. } \\
\text { Lockdown in metropolitan cities. } \\
\text { Rising temperatures. }\end{array}$ & Under Control \\
\hline 5 & Iran & $\begin{array}{l}\text { Shortage of drug and equipment. } \\
\text { Late lock down. } \\
\text { Lack of harsh preventive measures. } \\
\text { No fastly implemented mobility restrictions. } \\
\text { Economical sanctions. } \\
\text { No ban on massive religious gatherings. }\end{array}$ & Hit hard \\
\hline 6 & Italy & $\begin{array}{l}\text { Old age population. } \\
\text { Late lock down. } \\
\text { Lack of harsh preventive measures. } \\
\text { No fastly implemented mobility restrictions. }\end{array}$ & Hit hard \\
\hline 7 & Spain & $\begin{array}{l}\text { Old age population. } \\
\text { Delayed lock down. } \\
\text { Lack of harsh preventive measures. } \\
\text { No quick mobility restrictions. }\end{array}$ & Hit hard \\
\hline 8 & USA & $\begin{array}{l}\text { Delayed lock down. } \\
\text { Lack of harsh preventive measures. } \\
\text { Lack of prevention strategy. } \\
\text { No ban on mobility. }\end{array}$ & Hit hard \\
\hline
\end{tabular}

The preventive measures can be summarized depending on the stages of spread of the coronavirus (Table 4) [54].

Table 4. Condition and recommendations in COVID-19 pandemic.

\begin{tabular}{cll}
\hline No./Stage & Condition & \multicolumn{1}{c}{ Recommendations } \\
\hline & & Keeping personal hygiene, washing hands with clean soap \\
& for at least 20 seconds or using sanitizer with 75-80\% alcohol \\
& solution several times a day. \\
& Virus & Keeping rooms ventilated by opening windows and \\
& outside & removing respiratory droplets through air exchange. \\
human & Taking off shoes when entering home. \\
& body & Frequently sanitizing contacted surfaces (door handles etc.) \\
& & with 75-80\% alcohol solution. \\
& & Covering mouth/nose while sneezing, coughing by using \\
& disposable tissue and disposing it off into waste bins,
\end{tabular}


washing hands afterwards immediately.

Sneezing, coughing into elbow if no disposable tissue is available.

Staying away from sick people or diagnosed with COVID-19.

Avoiding visiting infected places, crowds, close contacts in public and hand shake.

Avoiding touching surfaces outside home with bare hands.

Avoiding public gatherings and socialization.

Avoiding touching face (mouth, nose and eyes) with unsanitized hands.

Giving proper attention to personal hygiene.

Observing own health condition and checking for signs of infection (by measuring temperature).

Avoiding close contacts in the household.

Practicing self-isolation and social-distancing.

Closing educational institutes and offices.

Using mask or N95 mask and gloves when going outside.

Avoiding animal farms and animals living outdoors.

Avoiding close contact with living animals/pets.

Preventing bug bites.

Avoiding eating uncooked, undercooked meat.

Avoiding eating meat of wild or carnivorous animals.

Not sharing cutlery and glasses.

Not sharing body fluids.

Disinfecting purchased items (boxes, packages and food) before use.

Using payment by card, avoiding touching money, disinfecting cash and purse.

Disinfecting mobile phones frequently.

Disposing clinical waste into leak-proof clinical waste bags.

Strict quarantine.

Gargling with hot water.

2 Virus is in Using mask to prevent spreading virus.

the Throat Patients with mild symptoms: supportive treatment by doctors and experts.

Avoiding close contacts in the household.

Virus is in Using mask to prevent spreading virus.

3 upper Depending on symptoms and complications, patients can be respiratory treated with supportive treatment by doctors and experts. system

4

Virus in 24/7 Close monitoring in ICU. Prevention of SARS-CoV-2 the lungs induced lung damage.

\section{Future Scope in Research}

At present, there is no specific vaccine or antiviral treatment for COVID-19. There is an urgent demand of effective, specific, active and affordable drugs. 
Physics based techniques plays important role in the field of structural engineering. Virus reproduction can be explained by X-ray crystallography and other techniques. The researchers will test how the structure of the coronavirus withstands changes in humidity and temperature, and under what conditions the virus falls apart. The results will help public health officials understand how the virus behaves under various environmental conditions, including in the changing seasons and in microclimates such as air-conditioned offices [57]. Chemistry, virology and immunology play a role in understanding viral structure, pathogenesis, vaccine-development and therapies. Computational chemistry can play a relevant role in revealing key mechanisms of viral transmission, host-guest response, drug delivery mechanisms and studies on the vulnerability of the virus. Artificial intelligence can help to deliver solutions for the vaccine production [51].

Antibiotics are used in the treatment of COVID-19 together with antiviral agents $[34,45]$. Antibiotic agents are needed in immune-suppressed, high-risk patients to eliminate bacterial co-infections, strengthen the immune system and speed up recovery [54]. The emergence of resistant microorganisms is another threat lingering behind the COVID-19 crisis. Already, antibiotic resistance was declared by the WHO as threat to human existence because of resistant pathogens, which do not respond to available antibiotic agents and even cause hospital-acquired nosocomial infections in patients $[58,59]$. This crisis was overshadowed and maybe overlooked in the ongoing fight against the coronavirus. The next pandemic striking mankind may result in higher mortality rates, if there are no new generation antibiotics ready to support the treatment of patients and to prevent nososcomial infections due to multidrug-resistant pathogens. Xiao et al. reported in a retrospective cohort study on 62 severe COVID-19 pneumonia patients in the intensive care unit at the Zhongnan Hospital of Wuhan University [60]. Incidence of hospital-acquired infections was directly related to hospitalization time and nosocomial infection by multidrug-resistant pathogens, with Acetinobacter baumanii as the most common strain isolated from the lower respiratory tract [60]. Nanotechnology is delivering promising future perspectives to develop vaccines and solutions against antibiotic resistance [61-66]. Jorquera et al. reported on nanovaccines against the respiratory syncytial virus [64]. Nanoparticles are effective drug-and vaccine carriers due to targeted delivery and controlled-release mechanisms [62,63]. Silver nanoparticles have antibacterial and antiviral potential [67-70]. Iodine is an important antimicrobial agents and has many applications in the medical field [71-74]. Complexed compounds with iodine offer potential agents with controlled release of iodine from polyiodides against pathogenic microorganisms [75-80]. The quest for antimicrobial agents should culminate in effective coating agents for masks, gloves, personal protective equipment, surfaces, wound-care products, surgical materials and medical equipment to prevent microbial adsorption. There is an urgent need for keeping surfaces, medical devices and equipment in hospitals free of pathogenic microorganisms in order to support the healing process and fast recovery of the patients [81]. This can be achieved by antimicrobials controlling the growth of multi-drug resistant microorganisms and preventing nosocomial infections. During a pandemic like COVID-19, such measurements can be life-saving. Coating masks, gloves and personal protective equipment with effective antimicrobials may protect the users from microbial infections.

\subsection{Plant based chemical compounds}

Polyphenols, flavonoids and further plant based natural products have high potential in the fight against pathogens [82-84]. A combination between biosynthesized nanocomposites with iodine content may have promising antimicrobial effects $[69,85]$. Essential oils of several plants like Prosopis cineraria (L.) Druce, allium sativum L. (garlic), zingiber officinale (ginger), curcuma longa (turmeric), cinnamomum zeylanicum (cinnamon) and rhus coriaria L. (sumac) have antimicrobial properties and support the immune system [69,86-92]. In the Mediterranean, Middle- and Far-East many plants and essential oils are used due to their health benefits and antimicrobial activities [89]. A recent article from Thuy et al. suggests garlic (Allium sativum L.) essential oil as natural antiviral compound [90]. Organosulfur compounds within the garlic essential oil may inhibit the ACE2 and PDB6LU7 receptor proteins [90]. Rhus coriaria L. has manifold properties and is used as antimicrobial agent since centuries [91]. Nigella sativa (black seed, kalonji) is an antimicrobial agent, stimulates the 
immune system and supports recovery from fatigue [92]. Hydroxychloroquine (HCQ), a less toxic derivative of chloroquine (CQ) is effective in inhibiting SARS-CoV-2, which is the component of black seed. According to the Indian council of Medical Research (ICMR), about $80 \%$ of infected patients experience common cold symptoms. Patients can take benefit of Genus Epidemicus homeopathy drugs as well from ayurveda as per prescription by doctor or expert.

\section{Discussion}

The outbreak of novel coronavirus (n-CoV-2019) originated from the Hunan seafood market at Wuhan, China where bats, snakes and other animals are sold [1,88]. COVID-19 rapidly spread across the globe $[1,45]$. The zoonotic source of SARS-CoV-2 is not confirmed, however, sequence-based analysis suggested bats as the key reservoir $[5,93]$. Wild animals should not enter the human food chain. There should be strict control mechanisms on life animal markets in China and other countries. A ban on eating wild animals and birds is of paramount significance to prevent further pandemics.

Reverse Real-time quantitative polymerase chain reaction rRT-qPCR is used for laboratory diagnosis in SARS-CoV-2. Due to low detection rate, there is a need to analyze with CT imaging [94,95]. To overcome this shortcoming, specific, sensitive, accurate and rapid diagnostic kit of SARS-CoV-2 in suspected patients is required. Until now, no promising clinical treatments or prevention strategies have been developed against human coronaviruses. However, the researchers are working to develop efficient therapeutic strategies to cope with the novel coronaviruses. As reported recently Hydroxychloroquine (HCQ), a less toxic derivative of chloroquine (CQ) maybe effective in inhibiting SARS-CoV-2. Most importantly, human coronaviruses specific vaccines and antiviral drugs should be designed that could be used against the current as well as future epidemics.

Prevention is better a strategy than cure. The COVID-19 pandemic is a challenge and can be controlled (Table 3). The experience and advances towards control and management of the global outbreak are relevant milestones. The lessons from the COVID-19 pandemic need to be learned, implemented, so mankind can survive future outbreaks unharmed. Authorities are required to take harsh and strict preventive measures including lockdown of entire areas. Countries like Taiwan, China and South Korea adopted successful preventive measures that should be followed worldwide. Health services staff members need to be specifically trained in crisis-management and decontaminating surfaces after each high-risk patient contact [96]. Health personnel and the general population require access to effective personal protective equipment. Different teams of doctors and experts should be immediately dispatched to other countries facing the outbreak to help control the spread of COVID-19. Measures to improve the health care system by developing the existing infrastructure is recommended.

Limiting transmissions is the most relevant step in the COVID-19 outbreak and further future pandemics (Table 3) [51,54]. We recommend developing new antimicrobial agents through bio-nanotechnology combined with well-known microbicides including plant derived products and polyiodides. Prevention of microbial biofilm formation and adsorption on medical equipment, masks, gloves and personal protective equipment is significant for the future of mankind. The use of artificial intelligence and computational chemistry is needed to act faster during development of vaccines and antimicrobial agents. International cooperation will ensure the survival of our species. The quest for vaccines and drugs should be orchestrated through cooperation and support mechanisms by all related institutions, governments and philanthropic organizations worldwide.

The epidemiological studies revealed that the majority of fatal cases are in the advanced age group, male and with pre-existing comorbidities [34]. Health literacy in the population should be improved through educational programs which will in turn reduce co-morbidities, depression and lower immunity in the population [37]. Governments and related institutions are urged to advocate increasingly healthy lifestyle with physical activity, healthy food intake and adequate serum 25-hydroxyvitamin D $(25(\mathrm{OH}) \mathrm{D})$ concentrations $[20,21]$. These factors are inversely related to 
obesity, diabetes, hypertension, metabolic syndrome, cardio-vascular and immune-suppression which seem to be the gateway to fatality in COVID-19 [17,19,33,34]. At the same time, environmental factors like pollution, temperature, humidity and latitude are related to the spread of the disease $[24,25]$. The increasing temperatures especially in the near equatorial regions will reduce infection rates drastically.

India, Pakistan, UAE, Gulf countries, Middle East and Africa seem not being hardly hit by the COVID-19 outbreak. This needs to be answered in an immunological context. India and UAE fastly reacted to the pandemic with strict and harsh preventive measurements which seem to be successful so far. Still questions arise, why the area is not as hard hit like other countries. Temperature, humidity and latitude may have prevented the uncontrolled spread of COVID-19 in India, Pakistan, UAE, other Gulf countries, the Middle East and Africa [24].

There are possible explanations for this phenomenon related to India and Pakistan. The copy of the virus in the Indian subcontinent may have irreversibly mutated and changed into a less virulent strain. At the same time, Pakistan, India, African continent are endemic for Malaria. The use of the traditional anti-malaria drugs chloroquine and it derivative hydroxyl-chloroquine made the population less liable. In comparison, other societies may be susceptible, because malaria is not endemic and the above anti-malaria drugs are not in use. The angiotensin-renin receptor of individuals in the Indian subcontinent does not fit to the viral legends and they differ from other nations. Low incidence of co-morbidities result in strong immune system. Additionally, BCG vaccination is stimulating cell mediated immunity (CMI). CMI is the part of the immune system that deals with the virally infected cells, acting in this respect in favor of subcontinent population. The BCG vaccine is not used in Italy, Spain or Germany. In the United Kingdom, BCG is given to infants in areas with a tuberculosis incidence around 40/100,000. These are infants with a parent or grandparent born in a high incidence country. The BCG vaccine induces an enhanced state of trained immunity [97].

A new hypothesis emerged recently related to lung involvement in COVID 19 [98]. Based on observations from the different studies published recently, Whenzhong et al. report, that the postmortem analysis revealed pulmonary thrombosis and not typical ARDS. They conclude, that COVID-19 does not cause pneumonia, nor ARDS. The virus structural protein may bind to hemoglobin displacing oxygen and iron [98]. The iron is released into the circulation and leads to toxicity causing inflammation of alveolar macrophages. The free iron released into the circulation is so toxic, that it causes oxidative damage to the lungs, which explains the bilateral - ground glass opacities seen on chest CT of those patients [98]. The authors claim, that this condition was mistakenly treated as bilateral pneumonia. Lung inflammation starts due to inability of both oxygen and carbon dioxide exchange. Hemoglobin loses its capacity to bind with oxygen thus oxygen is not supplied to major organs leading to resistant hypoxia coupled with very rapid multi-organ failures [98]. Patients do not benefit from invasive ventilation but may require frequent blood transfusions [98]. Heme is converted to porphyrin and subsequently chloroquine competes for binding to porphyrin. Favipiravir binds to the virus envelope protein with very high affinity and prevents entry into the cells as well as binding of structural proteins to porphyrin [98]. The body tries to compensate by elevating the rate of hemoglobin synthesis which explains high $\mathrm{Hb}$ levels in those patients [98]. Another compensatory mechanism is to deal with the iron load such as increasing ferritin [98]. This explains the very high ferritin observed in those patients.

Author Contributions: Conceptualization, Z.E., H.P. and S.H.B.; methodology, Z.E., H.P. and S.H.B.; software, Z.E. and H.P.; validation, Z.E., H.P. and S.H.B.; resources, Z.E.; data curation, Z.E.; writing-original draft preparation, H.P., Z.E. and A.A.S.; writing-review and editing, Z.E. and H.P.; visualization, A.A.S.; supervision, Z.E., H.P. and S.H.B.; project administration, Z.E., S.H.B. and H.P.; funding acquisition, S.H.B. All authors have read and agreed to the published version of the manuscript.

Funding: This work was kindly supported by the Deanship of Graduate Studies and Research, AU, Ajman, United Arab Emirates. 
Acknowledgments: We are thankful to Ms Fariyal S. Shaikh from New Vision University, Tiblisi, Georgia with her contributions to this paper by preparing the figures.

Conflicts of Interest: The authors declare no conflict of interest.

\section{References}

1. Li, X.; Wang, W.; Zhao, X.; Zai, J.; Zhao, Q.; Li, Y.; Chaillon, A. Transmission dynamics and evolutionary history of 2019-nCoV. J Med Virol. 2020, 92, 501-511. doi: 10.1002/jmv.25701.

2. Cui, J.; Li, F.; Shi, Z.L. Origin and evolution of pathogenic coronaviruses. Nat. Rev. Microbiol. 2019, 17, 181-192.

3. Weiss, S.R.; Leibowitz, J.L. Coronavirus pathogenesis. Adv. Virus Res. 2011, 81, 85-164.

4. Yang, D.; Leibowitz, J.L. The structure and functions of coronavirus genomic 3 and 5 ends. Virus Res. 2015, 206, 120-33.

5. Wong, A.C.P.; Li, X.; Lau, S.K.P.; Woo, P.C.Y. Global epidemiology of bat coronaviruses. Viruses 2019, 11, 174-191. doi:10.3390/v11020174.

6. Lai, C.-C.; Shih, T.-P.; Ko, W.-C.; Tang, H.-J.; Hsueh, P.-R. Severe acute respiratory syndrome coronavirus 2 (SARS-CoV-2) and corona virus disease-2019 (COVID-19): the epidemic and the challenges. Int. J. antimicrob. agents. 2020,105924.

7. Organization WH. Laboratory testing for coronavirus disease 2019 (COVID-19) in suspected human cases: interim guidance, 2 March 2020. World Health Organization, 2020.

8. Zhu, N.; Zhang, D.; Wang, W.; et al. A Novel Coronavirus from Patients with Pneumonia in China, 2019. N. Engl. J. Med. 2020, 382, 727-33.

9. Zheng, B.J.; Guan, Y.; Wong, K.H.; Zhou, J.; Wong, K.L.; Young, B.W.Y.; et al. SARS-related virus predating SARS outbreak, Hong Kong. Emerging Infect. Dis. 2004, 10(2), 176.

10. Shi, Z; Hu, Z. A review of studies on animal reservoirs of the SARS coronavirus. Virus research. 2008, 133(1), 74-87.

11. Paden, C.; Yusof, M.; Al Hammadi, Z.; Queen, K.; Tao, Y.; Eltahir, Y.; et al. Zoonotic origin and transmission of Middle East respiratory syndrome coronavirus in the UAE. Zoon. Publ. Health 2018; 65(3), 322-33.

12. Lu, R.; Zhao, X.; Li, J.; Niu, P.; Yang, B.; Wu, H.; et al. Genomic characterisation and epidemiology of 2019 novel coronavirus: implications for virus origins and receptor binding. Lancet 2020.

13. Chen, Z.-L.; Zhang, Q.; Lu, Y.; Guo, Z.-M.; Zhang, X.; Zhang, W.-J.; Guo, C.; Liao, C.-H.; Li, Q.-L.; Han, X.-H.; Lu, J.-H. Distribution of the COVID-19 epidemic and correlation with population emigration from wuhan, China. Chin. Med. J. 2020. doi: 10.1097/CM9.0000000000000782.

14. Péter B.; Tekeli, T.; Vizi, Z.; Dénes, A.; Bartha, F.A.; Röst, G. Risk Assessment of Novel Coronavirus COVID-19 Outbreaks Outside China. J. Clin. Med. 2020, 9, 571-583. doi:10.3390/jcm9020571.

15. Chan, J.F.-W.; Yuan, S.; Kok, K.-H.; To, K.K.-W.; Chu, H.; Yang, J.; et al. A familial cluster of pneumonia associated with the 2019 novel coronavirus indicating person-to-person transmission: a study of a family cluster. Lancet 2020.

16. Su, S.; Wong, G.; Shi, W.; et al., Epidemiology, Genetic recombination, and pathogenesis of coronaviruses, Trends Microbiol. 2016, 24, 490-502. https://doi.org/10.1016/j.tim.2016.03.003.

17. Park, M.; Cook, A.R.; Lim, J.T.; Sun, Y.; Dickens, B.L. A Systematic Review of COVID-19 Epidemiology Based on Current Evidence. J. Clin. Med. 2020, 9, 967-980. doi:10.3390/jcm9040967.

18. Deng, S.-Q.; Peng, H.-J. Characteristics of and Public Health Responses to the Coronavirus Disease 2019 Outbreak in China. J. Clin. Med. 2020, 9, 575-585. doi:10.3390/jcm9020575.

19. Liu, W.; Tao, Z.-W.; Lei, W.; Ming-Li, Y.; Kui, L.; Ling, Z.; Shuang, W.; Yan, D.; Jing, L.; Liu, H.-G.; Ming, Y.; $\mathrm{Yi}, \mathrm{H}$. Analysis of factors associated with disease outcomes in hospitalized patients with 2019 novel coronavirus disease. Chin. Med. J. 2020. doi: 10.1097/CM9.0000000000000775.

20. Grant, W.B.; Lahore, H.; McDonnell, S.L.; Baggerly, C.A.; French, C.B.; Aliano, J.L.; Bhattoa, H.P. Evidence that Vitamin D Supplementation Could Reduce Risk of Influenza and COVID-19 Infections and Deaths. Nutr. 2020, 12, 988-1007. doi:10.3390/nu12040988.

21. Edis, Z; Haj Bloukh, S. Vitamin D Deficiency- Main Factors Affecting The Serum 25-Hydroxyvitamin D ([25(Oh)D]) Status And Treatment Options. Int. J. Res. 2016, 3(01), 197-211. 
22. Haj Bloukh, S.; Edis, Z.; Qassim, S.; Al-Hariri, Y. Vitamin D deficiency practice among female medical students in Ajman, UAE. Int. Res. J. Pharm. 2018, 9(7), 53-58. http://dx.doi.org/10.7897/2230-8407.097125

23. Edis, Z.; Haj Bloukh, S.; Qassim, S.; Al-Hariri, Y. Int. Res. J. Pharm. 2018, 9(8), 36-41, http://dx.doi.org/10.7897/2230-8407.098161.

24. Sajadi, M.M.; Habibzadeh, P.; Vintzileos, A.; Shokouhi, S.; Mirales-Wilhelm, F.;Amoroso, A. Temperature, humidity, and latitude analysis to predict potential spread and seaonality for COVID-19.

25. Qu, G.; Li, X.; Jiang, An Imperative Need for Research on the Role of Environmental Factors in Transmission of Novel Coronavirus (COVID-19). G. Env. Sc. Techn. 2020, 54(7), 3730-3732. https://dx.doi.org/10.1021/acs.est.0c01102.

26. Ibrahim, N.A.; Edis, Z.; Al-Owais, K.S. Adherence of geriatric patients and their beliefs toward their medicines in the United Arab Emirates. J. Pharm. Bioall. Sci. 2020, 12, 22-30. https://doi.org/10.4103/jpbs.JPBS_93 19.

27. de Wit, E.; van Doremalen, N.; Falzarano, D.; Munster, V.J. SARS and MERS: Recent insights into emerging coronaviruses. Nat. Rev. Microbiol. 2016, 14, 523-534.

28. Wu, Z.; McGoogan, J.M. Characteristics of and Important Lessons from the Coronavirus Disease 2019 (COVID-19) Outbreak in China: Summary of a Report of 72314 Cases from the Chinese Center for Disease Control and Prevention. J.A.M.A. 2020.

29. Deng, Y.; Liu, W.; Liu, K.; Fang, Y.-Y.; Shang, J.; Zhou, L.; Wang, K.; Leng, F.; Wei, S.; Chen, L.; Liu, H.-G. Clinical characteristics of fatal and recovered cases of coronavirus disease 2019 (COVID-19) in Wuhan, China-a retrospective study. J. Clin. Med. 2020. doi: 10.1097/CM9.0000000000000824.

30. Mirsoleymani, S.; Nekooghadam, S.M. Risk Factors for Severe Coronavirus Disease 2019 (COVID-19) Among Iranian Patients: Who Was More Vulnerable? Lancet 2020. Preprint. https://ssrn.com/abstract=3566216.

31. Luo, L.; Liu, D.; Liao, X.-L; Wu, X.-B.; Jing, Q.-L.; Zheng, J.-Z.; et al. Modes of Contact and Risk of Transmission in COVID-19: A Prospective Cohort Study 4950 Close Contact Persons in Guangzhou of China. Lancet 2020. Preprint. https://ssrn.com/abstract=3566149.

32. Chen, Z.M.; Fu, J.F.; Shu, Q.; Chen, Y.H.; Hua, C.Z.; Li, F.B.; Lin, R.; Tang, L.F.; Wang, T.L.; Wang,W.; et al. Diagnosis and treatment recommendations for pediatric respiratory infection caused by the 2019 novel coronavirus. World J. Pediatr. 2020.

33. Lui, K.; Fang, Y.-Y.; Deng, Y.; Wei L.; Wang, M.-F.; Ma, J.-P.; Xiao, W.; Wang, Y.-N.; Zhong, M.-H.; Li, C.-H.; Li, G.-C.; Liu, H.-G. Clinical characteristics of novel coronavirus cases in tertiary hospitals in Hubei Province. Chin. Med. J. 2020. doi: 10.1097/CM9.0000000000000744.

34. Borges do Nascimento, I.J.; Cacic, N.; Abdulazeem, H.M.; von Groote, T.C.; Jayarajah, U.; Weerasekara, I.; Esfahani, M.A.; 8 , Civile, V.T.; Marusic, A.; Jeroncic, A.; Junior, N.C.; Pericic, T.P.; Zakarija-Grkovic, I.; Guimarães, S.M.M.; Bragazzi, N.L.; Bjorklund, M.; Sofi-Mahmudi, A.; Altujjar, M.; Tian, M.; Arcani, D.M.C.; O'Mathúna, D.P.; Marcolino, M.S. Novel Coronavirus Infection (COVID-19) in Humans: A Scoping Review and Meta-Analysis. J. Clin. Med. 2020, 9, 941-955. doi:10.3390/jcm9040941.

35. Chaolin, H.; Yeming, W.; Xingwang, L.; et al. Clinical features of patients infected with 2019 novel coronavirus in Wuhan, China. Lancet 2020; 395, 497-506.

36. Weijie, G.; Zhengyi, N.; Yu, H.; et al. Clinical characteristics of 2019 novel coronavirus infection in China. MedRxiv 2020.

37. Nguyen, H.C; Nguyen, M.H.; Do, B.N.; Tran, C.Q.; Nguyen, T.T.P.; Pham, K.M.; Pham, L.V.; Tran, K.V.; et al.; People with Suspected COVID-19 Symptoms Were More Likely Depressed and Had Lower Health-Related Quality of Life: The Potential Benefit of Health Literacy. J. Clin. Med. 2020, 9, 965-983; doi:10.3390/jcm9040965.

38. Holshue, M.L.; DeBolt, C.; Lindquist, S.; et al. First Case of 2019 Novel Coronavirus in the United States. N Engl. J. Med. 2020. Epub ahead of print.

39. Chung, M.; Bernheim, A.; Mei, X.; Zhang, N. CT Imaging Features of 2019 Novel Coronavirus (2019-nCoV). Radiology 2020; 4 . Epub ahead of print.

40. Jin, Y.-H.; Cai, L.; Cheng, Z.-S.; et al. A rapid advice guideline for the diagnosis and treatment of 2019 novel coronavirus (2019-nCoV) infected pneumonia (standard version). Mil. Med. Res. 2020, 7, 4.

41. Zhou, P.; Yang, X.L.; Wang, X.G.; et al. A pneumonia outbreak associated with a new coronavirus of probable bat origin. Nature 2020. https://doi.org/10.1038/s41586-020-2012-7. 
42. Corman, V.M.; Landt, O.; Kaiser, M.; et al. Detection of 2019 novel coronavirus (2019-nCoV) by real-time RT-PCR. Euro. Surveill. 2020, 25. https://doi.org/10.2807/1560-7917.ES.2020.25.3.2000045.

43. Xie, X.; Zhong, Z.; Zhao, W.; et al. Chest CT for Typical 2019-nCoV Pneumonia: Relationship to Negative RT-PCR Testing. Radiology 2020, 200343.

44. Diseases TLI. Challenges of coronavirus disease 2019. Lancet Infect. Dis. 2020, S1473-3099, 30072-30074.

45. Ren, L.-L.; Wang, Y.-M.; Wu, Z.-Q.; Xiang, Z.-C.; Guo, L.; Xu, T.; Jiang, Y.-Z.; Xiong, Y.; Li, Y.-J.; Li, X.-W.; et al. Identification of a novel coronavirus causing severe pneumonia in human: A descriptive study. Chin. Med. J. (Engl.) 2020. doi: 10.1097/CM9.0000000000000722.

46. Jung, S.M.; Kinoshita, R.; Thompson, R.N.; Linton, N.M.; Yang, Y.; Akhmetzhanov, A.R.; Nishiura, H. Epidemiological Identification of A Novel Pathogen in Real Time: Analysis of the Atypical Pneumonia Outbreak in Wuhan, China, 2019-2020. J. Clin. Med. 2020, 9, 637-646. doi:10.3390/jcm9030637.

47. Wang, M. et al. Remdesivir and chloroquine effectively inhibit the recently emerged novel coronavirus (2019-nCoV) in vitro. Cell Res. 2020, 30, 269 -271.

48. Tu, Y.-F.; Chien, C.-S.; Yarmishyn, A.A.; Lin, Y.-Y.; Luo, Y.-H.; Lin, Y.-T.; et al. A Review of SARS-CoV-2 and the Ongoing Clinical Trials. Int. J. Mol. Sci. 2020, 21, 2657-2678. doi:10.3390/ijms21072657.

49. Gautret, P.; Lagier, J.-C.; Parola, P.; Hoang, V.T.; Meddeb, L.; Mailhe, M.; Doudier, B.; Courjon, J.; Giordanengo, V.; Vieira, V.E.; et al. Hydroxychloroquine and azithromycin as a treatment of COVID-19:results of an open-label non-randomized clinical trial. Int. J. Antimicrob. Agents 2020, 105949. doi:10.1016/j.ijantimicag.2020.105949.

50. Fan, Hua-Hao; Wang, Li-Qin; Liu, Wen-Li; An, Xiao-Ping; Liu, Zhen-Dong; He, Xiao-Qi; Song, Li-Hua; Tong, Yi-GangSection Editor(s): Wei, Pei-Fang. Repurposing of clinically approved drugs for treatment of coronavirus disease 2019 in a 2019-novel coronavirus (2019-nCoV) related coronavirus model. Chin. Med. J. 2020. doi: 10.1097/CM9.0000000000000797.

51. Lin, John1,2; Ouyang, Jing3; Peng, Xiao-Rong1,2,4; Isnard, Stéphane1,2; Fombuena, Brandon1,2,5; Routy, Jean-Pierre1,2,6; Chen, Yao-Kai3Section Editor(s): Lyu, Peng. Potential therapeutic options for coronavirus disease 2019 using knowledge of past outbreaks to guide future treatment. Chin. Med. J. 2020. doi: 10.1097/CM9.0000000000000816.

52. Tang, B.; Wang, X.; Li, Q.; Bragazzi, N.L.; Tang, S.; Xiao, Y.; Wu, J. Estimation of the Transmission Risk of the 2019-nCoV and Its Implication for Public Health Interventions. J. Clin. Med. 2020, 9, 462., Thompson, R.N. Novel Coronavirus Outbreak in Wuhan, China, 2020: Intense Surveillance Is Vital for Preventing Sustained Transmission in New Locations. J. Clin. Med. 2020, 9, 498.

53. Koo, J.R.; Cook, A.R.; Park, M.; Sun, Y.; Sun, H.; Lim, J.T.; Tam, C.; Dickens, B.L. Interventions to mitigate early spread of SARS-CoV-2 in Singapore: A modelling study. Lancet Infect. Dis. 2020. Published online: https://doi.org/10.1016/ S1473-3099(20)30162-6.

54. Yan, Y.; Shin, W.I.; Pang, Y.X.; Meng, Y.; Lai, J.; You, C.; Zhao, H.; Lester, E.; Wu, T.; Pang, C.H. The First 75 Days of Novel Coronavirus (SARS-CoV-2) Outbreak: Recent Advances, Prevention, and Treatment. Int. J. Environ. Res. Public Health 2020, 17, 2323. doi:10.3390/ijerph17072323.

55. South Korea learned its successful COVID-19 strategy from a previous coronavirus outbreak - MERS. Available online: https://thebulletin.org/2020/03/south-korea-learned-its-successful-covid-19-strategy-from-a-previous-coro navirus-outbreak-mers/\# (accessed on 31 March 2020).

56. Lessons on handling the COVID-19 outbreak from Taiwan. Available online: https://ipolitics.ca/2020/03/17/lessons-on-handling-the-covid-19-outbreak-from-taiwan/. (accessed on 17 March 2020).

57. Wu, J.T.; Leung, K.; et al, Estimating clinical severity of COVID-19 from the transmission dynamics in Wuhan, China. Nature Medicine 2020.

58. Shrivastava, S.; Shrivastava, P.; Ramasamy, J. World health organization releases global priority list of antibiotic-resistant bacteria to guide research, discovery, and development of new antibiotics. J. Med. Soc. 2018, 32, 76-77, doi:10.4103/jms.jms_25_17.

59. Mulani, M.S.; Kamble, E.E.; Kumkar, S.N.; Tawre, M.S.; Pardesi, K.R. Emerging Strategies to Combat ESKAPE Pathogens in the Era of Antimicrobial Resistance: A Review. Front. Microbiol. 2019, 10, 539-563. doi: 10.3389/fmicb.2019.00539.

60. Xiao, X.; Liu, Q.; Zhu, X.; Li, Y.; Li, X. Risk Factors Associated with Hospital-Acquired Infections for COVID-19 Patients in ICU. Lancet 2020. Preprint. https://ssrn.com/abstract=3564427. 
61. Gomes, A.C.; Mohsen, M.; Bachmann, M.F. Harnessing Nanoparticles for Immunomodulation and Vaccines. Vaccines 2017, 5, 6-21. doi:10.3390/vaccines5010006.

62. Vijayan, V.; Mohapatra, A.; Uthaman, S.; Park, I.-K.. Recent Advances in Nanovaccines Using Biomimetic Immunomodulatory Materials. Pharmaceutics 2019, 11, 534-561. doi:10.3390/pharmaceutics11100534.

63. Chattopadhyay, S.; Chen, J.Y.; Chen, H.W.; Hu, C.M.J. Nanoparticle Vaccines Adopting Virus-like Features for Enhanced Immune Potentiation. Nanotheranostics 2017, 1, 244-260.

64. Patricia A. Jorquera and Ralph A. Tripp. Synthetic Biodegradable Microparticle and Nanoparticle Vaccines against the Respiratory Syncytial Virus. Vaccines 2016, 4, 45. doi:10.3390/vaccines404004.

65. Edis, Z.; Haj Bloukh, S.; Ashames, A.; Ibrahim, M. Copper-Based Nanoparticles, their chemistry and Antibacterial properties: A Review. In Chemistry for a clean and healthy Planet, $1^{\text {st }}$ ed.; Ramasami, P.; Gupta Bhowon, M.; Jhaumeer Laulloo, S.; Li Kam Wah, H., Ed.; Springer Nature AG: Switzerland, 2019; pp. 401-428, ISBN-13: 978-3-030-20282-8. doi: 10.1007/978-3-030-20283-5_24.

66. Kanwar, R.; Rathee, J.; Salunke, D.B.; Mehta, S.K. Green Nanotechnology-Driven Drug Delivery Assemblies. ACS Omega 2019, 4, 8804-8815. doi: 10.1021/acsomega.9b00304.

67. Galdiero, S.; Falanga, A.; Vitiello, M.; Cantisani, M. Marra, V.; Galdiero, M.. Silver Nanoparticles as Potential Antiviral Agents. Molecules 2011, 16, 8894-8918; doi:10.3390/molecules16108894.

68. Reda, M.; Ashames, A.; Edis, Z.; Bloukh, S.; Bhandare, R.; Abu Sara, H. Green Synthesis of Potent Antimicrobial Silver Nanoparticles Using Different Plant Extracts and Their Mixtures, Processes 2019, 7, 510; doi:10.3390/pr7080510.

69. Edis, Z.*; Haj Bloukh, S.; Ibrahim, M.R.; Abu Sara, H. "Smart" antimicrobial nanocomplexes with potential to decrease surgical site infections (SSI). Pharmaceutics under review.

70. Khan, A.U.; Khan, M.; Khan, M.M. Antifungal and Antibacterial Assay by Silver Nanoparticles Synthesized from Aqueous Leaf Extract of Trigonella foenum-graecum. BioNanoSci. 2019, 1-6, published online. https://doi.org/10.1007/s12668-019-00643-x.

71. Kaiho, T. In Iodine Chemistry and Applications, 1st ed.; Kaiho, T., Ed.; John Wiley \& Sons, Inc.: Hoboken, NJ, USA, 2015; pp. 15-410, ISBN-13: 978-1-118-46629-2.

72. Zhao, G.; He, C.; Zhou, W.; Hooper, J.P.; Imler, G.H.; Parrish, D.A.; Shreeve, J.M. Control of Biohazards: A High Performance Energetic Polycyclized Iodine-Containing Biocide. Inorg. Chem. 2018, 57, 8673-8680.

73. Gao, T.; Fan, H.; Wang, X.; Gao, Y.; Liu, W.; Chen, W.; Dong, A.; Wang, Y.J. Povidone-Iodine-Based Polymeric Nanoparticles for Antibacterial applications. ACS Appl. Mater. Interfaces 2017, 9, 25738-25746.

74. Viswanathan, K.; Babu, D. B.; Jayakumar, G.; Raj, G. D.: Anti-microbial and skin wound dressing application of molecular iodine nanoparticles. Mater. Res. Express 2017, 4, 104003.

75. Edis, Z.; Haj Bloukh, S.; Abu Sara, H.; Bhakhoa, H.; Rhyman, L.; Ramasami, P.: "Smart" triiodide compounds: Does halogen bonding influence antimicrobial activities? Pathogens 2019, 8, 182-202. https://doi.org/10.3390/pathogens8040182.

76. Haj Bloukh, S.; Edis, Z. Structure and Antimicrobial properties of bis $\left(1,4,7,10\right.$-tetraoxacyclododecane- $\left.\kappa 4 \mathrm{O}, \mathrm{O}^{\prime}, \mathrm{O}^{\prime \prime}, \mathrm{O}^{\prime \prime \prime}\right)$ cesium pentaiodide, C16H32CsI5O8. Z. Kristallogr. NCS 2020, in print. https://doi.org/10.1515/ncrs-2020-0057.

77. Haj Bloukh, S.; Edis, Z. Halogen bonding in Crystal structure of bis $\left(1,4,7,10\right.$-tetraoxacyclododecane- $\left.\kappa^{4} \mathrm{O}, \mathrm{O}^{\prime}, \mathrm{O}^{\prime \prime}, \mathrm{O}^{\prime \prime \prime}\right)$ cesium triiodide.

78. Edis, Z.; Bloukh, S.H. Preparation and structural and spectroscopic characterization of triiodides [M(12-crown-4)2]I3 with M= Na and Rb. Z. Nat. 2014, 69, 995-1002.

79. Edis, Z.; Bloukh, S.H. Preparation and structural and spectroscopic characterization of a pentaiodide [Rb(12-crown-4) 2]I5. Z. Nat. 2013, 68, 1340-1346.

80. Reiss, G.J. Halogen and hydrogen bonding in the layered crystal structure of 2-iodoaniliniumtriiodide, C6H7I4N. Z. Kristallogr. NCS 2019, 234(5), 899-902.

81. Riau, A.K.; Aung, T.T.; Setiawan, M.; Yang, L.; Yam, G.H.F.; Beuerman, R.W.; Venkatraman, S.S.; Mehta, J.S. Surface Immobilization of Nano-Silver on Polymeric Medical Devices to Prevent Bacterial Biofilm Formation. Pathogens 2019, 8, 93-111. doi: 10.3390/pathogens8030093.

82. Anand, U.; Jacobo-Herrera, N.; Altemimi, A.; Lakhssassi, N. A Comprehensive Review on Medicinal Plants as Antimicrobial Therapeutics: Potential Avenues of Biocompatible Drug Discovery. Metabolites 2019, 9, 258-271. doi: 10.3390/metabo9110258. 
83. Zhao, Q.; Luan, X.; Zheng, M.; Tian, X.-H.; Zhao, J.; Zhang, W.-D.; Ma, B.-L. Synergistic Mechanisms of Constituents in Herbal Extracts during Intestinal Absorption: Focus on Natural Occurring Nanoparticles. Pharmaceutics 2020, 12, 128-146. doi: 10.3390/pharmaceutics12020128.

84. Zhang, D.; Gan, R.-Y.; Farha, A.K.; Kim, G.; Yang, Q.-Q.; 1 , Shi, X.-M.; et al. Discovery of Antibacterial Dietary Spices That Target Antibiotic-Resistant Bacteria. Microorganisms 2019, 7, 157-178. doi:10.3390/microorganisms7060157.

85. Manchanda, G.; Sodhi, R.K.; Jain, U.K.; Chandra, R.; Madan, J. Iodinated curcumin bearing dermal cream augmented drug delivery, antimicrobial and antioxidant activities. J. Microencapsul. 2018, 35, 49-61.

86. Islam, M.W.; Bloukh, S.H.; Edis, Z.; Bhandare, R.R. Emerging Phytochemicals and Bioactive Compounds from a Desert Plant Prosopis cineraria (L.) Druce and Future Prospects. In Chemistry for a clean and healthy Planet, $1^{\text {st }}$ ed.; Ramasami, P.; Gupta Bhowon, M.; Jhaumeer Laulloo, S.; Li Kam Wah, H., Ed.; Springer Nature AG: Switzerland, 2019; pp. 401-428, ISBN-13: 978-3-030-20282-8. doi: 10.1007/978-3-030-20283-5_2.

87. Yu, Z.; Tang, J.; Khare, T.; Kumar, V. The alarming antimicrobial resistance in ESKAPEE pathogens: Can essential oils come to the rescue? Fitoterapia 2020, 40, 104433. doi.org/10.1016/j.fitote.2019.104433.

88. Man, A.; Santacroce, L.; Jacob, R.; Mare, A.; Man, L. Antimicrobial Activity of Six Essential Oils Against a Group of Human Pathogens: A Comparative Study. Pathogens 2019, 8, 15-26. doi:10.3390/pathogens8010015.

89. Maccelli, A.; Vitanza, L.; Imbriano, A.; Fraschetti, C.; Filippi, A.; Goldoni, P.; Maurizi, L.; Ammendolia, M.G.; Crestoni, M.E.; Fornarini, S.; Menghini, L.; Carafa, M.; Marianecci, C.; Longhi, C.; Rinaldi, F. Satureja montana L. Essential Oils: Chemical Profiles/Phytochemical Screening, Antimicrobial Activity and O/WNanoEmulsion Formulations. Pharmaceutics 2020, 12, 7. doi:10.3390/pharmaceutics12010007.

90. Thuy, B.T.P.; My, T.T.A.; Hai, N.T.T.; Hieu, L.T.; Hoa, T.T. et al. Investigation into SARS-CoV-2 Resistance of Compounds in Garlic Essential Oil. ACS Omega 2020. ASAP. https://dx.doi.org/10.1021/acsomega.0c00772.

91. Asgarpanah, J.*; Saati, S. An overview on phytochemical and pharmacological properties of Rhus coriaria L. Res. J. Pharmacogn. 2014, 1(3), 47-54.

92. Almatroudi, A.; Khadri, H.; Azam, M.; Rahmani, A.H.; 1 Al Khaleefah, F.K.; Khateef, R.; Ansari, M.A.; Allemailem, K.S. Antibacterial, Antibiofilm and Anticancer Activity of Biologically Synthesized Silver Nanoparticles Using Seed Extract of Nigella sativa. Processes 2020, 8, 388-402. doi:10.3390/pr8040388.

93. Li, Q.; Guan, X.; Wu, P.; Wang, X.; Zhou, L.; Tong, Y.; et al. Early transmission dynamics in Wuhan, China, of novel coronavirus-infected pneumonia. N. Engl. J. Med. 2020. https://doi.org/10.1056/NEJMoa2001316.

94. Shi, H.; Han, X.; Zheng, C. Evolution of CT Manifestations in a Patient Recovered from 2019 Novel Coronavirus (2019-nCoV) Pneumonia in Wuhan, China. Radiology 2020, 200269. https://doi.org/10.1148/radiol.2020200269.

95. Pan, Y.; Guan, H.; Zhou, S. et al. Initial CT findings and temporal changes in patients with the novel coronavirus pneumonia (2019-nCoV): a study of 63 patients in Wuhan, China. Eur. Radiol. 2020. https://doi.org/10.1007/s00330-020- 06731-x.

96. Mirza, S.K.; Tragon, T.R.; Fukui, M.B.; Hartman, M.S.; Hartman, A.L. Microbiology for radiologists: how to minimize infection transmission in the radiology department. Radiographics 2015, 35, 1231-44.

97. Benn, C.S.; Netea, M.G.; Selin, L.K.; Aaby, P. A small jab - a big effect: nonspecific immunomodulation by vaccines. Trends Immunol. 2013, 34(9), 431-439. doi: 10.1016/j.it.2013.04.004.

98. Wenzhong, L.; Hualan, L. COVID-19: Attacks the 1-Beta Chain of Hemoglobin and Captures the Porphyrin to Inhibit Human Heme Metabolism. ChemRxiv. 2020. Preprint. https://doi.org/10.26434/chemrxiv.11938173.v6. 